\section{Die galvanokaustische Sonde für den Tränenkanal.}

Von Prof. Dr. M. Peschel, Augenarzt in Frankfurt a. M.

Bereits 1894 (Zentralblatt für Augenheilkunde S. 229) habe ich eine Sonde behufs galvanokaustischer Behandlung der Tränenwege konstruiert und sie seitdem vielfach in Fallen von Dacryocystoblennorrhoe oder Stenose der Tranenwege angewendet teils bei meinem reichlichen Krankenmaterial in Turin (jährlich etwa 100 bis 150 derartige Fälle), teils seit 1898 in meinem jetzigen Wirkungs. kreise in Frankfurt, wobei natürlich nur eine Auswahl der betreffenden Patienten dieser speziellen Behandlungsart unterzogen wurde. Die Sonde wurde von mir bald nach der obigen Veröffentlichung modifiziert, und zwar in der Art, daß ich die erglühende Stelle von der Spitze hinweg nach einer Seite verlegte, wodurch die Spitze resistenter wurde. Neuerdings hat mir endlich die Firma Reiniger, Gebbert \& Schall in Erlangen das vollkommenste Modell hergestellt, welches nunmehr allen Anforderungen ganz vorzüglich entspricht und von dieser Firma für sehr mäBigen Preis zu beziehen ist. In dem frïheren Modelle wurden die zwei für sich recht dünnen Platindrahte nebst der Isolationsschicht durch feinste Elfenbeinnieten zusammengchalten, wodurch die Resistenz der betreffenden Stellen stark vermindert wurde. Im neuen Modell wurden die zwei Drahtschenkel nebst der Isolation schraubenartig torquiert, womit die Sonde bedeutend an Stabilität und Resistenz gewinnt und ïberdies die Isolation unverrückbar befestigt ist. Ferner wurde zwecks Vermeidung eines zu hohen Preises die Sonde statt aus Platin aus vernickeltem Kupferdrahte konstruiert und pur die zur Glühung zu bringende Stelle aus Platin hergestellt. Der Durchmesser des Kauters, dessen Figur hier folgt, beträgt nur 1,5 mm, weshalb er mit Leichtigkeit nach vorgän-

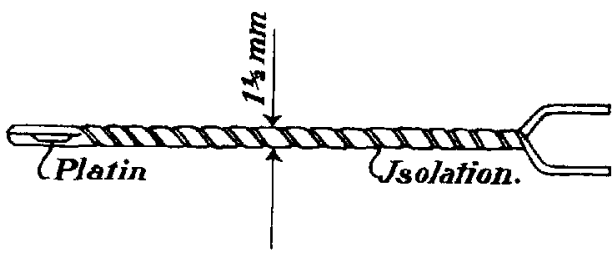
giger Sondierung der Tränenwege eingeführt werden kann

Bei der Handhabung der Sonde ist stets zu berücksichtigen, daß sie sich im ganzen beträchtlich erhitzt, wenn der Stromschluß

länger als etwa eine Sekunde dauert. Diese Erhitzung ist möglichst zu vermeiden, teils der Schmerzhaftigkeit für den Patienten wegen, teils der Aetzwirkung halber, welche die Sonde in ihrer ganzen Länge ausüben kann und welche für den Canaliculus lacrimalis schädliche Folgen hat. Die diffuse Erhitzung des Kauters ist übrigens geringer bei der, mit den feuchten Körpergeweben in Berührung stehenden, eingeführten als bei der freien Sonde, welche man experimenti causa mit dem Strome in Verbindung setzt. Das Erglühen des Platindrahtes während einer Sekunde ist für unsere $Z$ wecke vollständig genügend, es muß nur entsprechend oft wiederholt und die Kauterisation an verschiedenen Stellen des Kanals. resp. Sackes appliziert werden, indem die Sonde teils in der Höhe verschoben, teils nach allen Seiten gedreht wird, da ja nur ihre eine Seite wirksam ist. Das bei jeder Stromeinschaltung erfolgende Erglühen des versteckten, kleinen Platindrahtes macht sich durch ein knisterndes Kochen dem Gehör bemerkbar. Wenn man im Tränensacke operiert, so kann stärkeres Frglühen auch dem Auge sichtbar werden, indem durch die Weichteile hindurch ein unheimliches, rotes Aufleuchten stattfindet. Die nachfolgende Reaktion ist so gering, daß ich die Sonde in vielen Fällen zum Zwecke einer Schnellkur täglich während einer Woche anwandte, wobei ich in jeder Sitzung etwa 10 bis 15 mal den Strom je eine Sekunde lang mit Intervallen einschaltete, welche von der Erhitzung der Sonde abhingen und meist einige Sekunden betrugen. Die Erhitzung des Kauters kontrolliert man sehr einfach durch direktes Betasten mit den Fingern, abgesehen davon, dab bei eintretender Erhitzung des oberen Teils der Sonde der Patient alsbald wegen der Schmerzhaftigkeit rebellieren wird. In manchen Fällen folgt etwas stärkere Reaktion, die sich namentlich durch leichtes
Oedem der nächstliegenden Haut, auch der Lider kundgibt. Alsdann ist natürlich mit weiteren Applikationen zu warten, bis die Reizung vorüber ist. Erfolgt das Erglühen wegen Stromdefekts nur unvollständig, so kann ein unliebsamer Unfall eintreten, nämlich es bedeckt sich der Platindraht mit koaguliertem Eiweiß, welches mit dem anliegenden Gewebe fest verbunden ist und beim Herausziehen des Kauters reißt man ein Stückchen Gewebe, resp. Schleimhaut heraus. Dadurch kann überdies eine mehr oder weniger heftige Blutung hervorgerufen werden, welche aber durch neue Einführung des Kauters an dieselbe Stelle unter Anwendung einer zur Galvanokaustik genügenden Stromstärke jedenfalls, wenn nötig. sistiert werden kann. Die Reinigung der Sonde nach jeder Sitzung erfordert ganz besondere Aufmerksamkeit, da der zarte Platindraht nicht beschädigt werden darf. Am besten verkohlt man durch erneuten Stromanschluß die koagulierten Massen, welche den Draht umgeben und geht mit einer feinen Nähnadel zwischen die zwei Schenkel des Kauters vorsichtig ein, um die Spitze richtig zu reinigen. Erhitzen der Spitze über der Spiritusflamme ist nicht anzuraten, da die so häufig notwendige Wiederholung dieser Manipulation das Metall schädigt. Zur Desinfektion wähle man naturlich eine das Metall nicht angreifende Flüssigkeit. Die Sonde vertràgt übrigens auch das Kochen.

Die Indikation zur Galvanokaustik der Tränenwege geben vor allem die chronischen Prozesse, und ich halte dabei noch immer an den in meiner ersten Arbeit 1894 gegebenen Prinzipien fest. Die Wirkung ist rasche Verringerung der Eitersekretion und Herstellung der Durchgängigkeit des Kanals. Letztere ist oft nur durch tiefe Aetzung der strikturierten Stellen während mehrerer Sitzungen zu erreichen, auch ist bei wieder erfolgender Verengerung Wiederholung energischer Galvanokaustik mit nachträglich einige Zeit fortgesetztem Sondieren nötig. Die Resultate der galvanokaustischen Behandlung haben sich mir jedenfalls als besser und dauernder ergeben als die irgend einer andern konservativen Methode, welche die Erhaltung der Durchgängigkeit der Tränenwege zum Objekte hat. Ueberdies werden sehr energische Effekte in der schonendsten Art beigebracht, und in dieser Beziehung hat die Galvanokaustik auch einen Forrang vor der Elektrolyse der Tranenwege, welche mir zwar bei energischer Anwendung auch vielfach gute Resultate gegeben hat, aber öfter stärkere Reaktion zur Folge hat als jene und bei festen Strikturen weit weniger wirksam ist. 